\title{
FACTORS AFFECTING THE SUCCESS OF THE USE OF ELECTRONIC MEDICAL RECORD (EMR) IN NURSING SERVICES IN HOSPITAL
}

\author{
Astri Safariah ${ }^{a^{*}}$ \\ ${ }^{a)}$ Universitas Indonesia, Jakarta, Indonesia \\ ${ }^{*}$ Corresponding Author : astri.safariah@ui.ac.id
}

Article history: received 28 December 2018; revised 19 January 2019; accepted 25 January 2019

\begin{abstract}
Abstrak. The hospital is a health service facility that is integrated with the nursing service system. With the advancement of technology, the services of the congregation must be effective and efficient both in terms of service time so that the quality of service to patients is still prioritized. Nurses must be prepared to face challenges in the era of technological advances so that included in the use of electronic medical records, especially in the nursing service order, the factors that influence the success of EMR are nurses as users must be proficient in using computers, management must always evaluate and communicate with EMR use and IT systems themselves must be easier, faster and more flexible to use so nurses are more confident in using EMR
\end{abstract}

Keywords: Hospital; Nurse; EMR

\section{INTRODUCTION}

The hospital is one of the health facilities where health efforts are organized. Health effort is every activity to maintain and improve health which aims to realize optimal health status for the community. Data management in hospitals is one important component in realizing a quality hospital service. According to the Decree of the Minister of Health of the Republic of Indonesia No. 286/Menkes/SK/VI/ 1990 , a hospital is a means of health efforts that organizes health activities and can be utilized for education and research, outpatient services, inpatient services, emergency services, medical services and non-medical services.

The rapid development of technology and science in the order of nursing services impacts the need to increase the knowledge and abilities of nurses in accordance with their competencies including the ability of nurses to use technology. Nurses are providers of nursing services to clients, families, and the community in the form of nursing care. This development has an impact on improving the quality of nursing services. Improving the quality of service should be in line with the quality provided by nurses according to their competence. Nurses are providers of nursing services to individuals, families and community groups. Nursing services in the form of Nursing Care starting from the assessment, nursing diagnoses, planning, implementation to evaluation.

Good nursing services are integrated with an adequate documentation system. Electronic medical record is the answer for millennial nurses about the ease, effectiveness and sophistication in providing services to patients. In Taiwan Electronic Medical records have been applied since 1970 (Narattharaksa [1]) according to them that technology-based information systems are very important because it is related to the service system for patients, from the effectiveness of time, and the ease in getting. But this is still under observation because, there are still problems in the micro, namely the confidence of the nurse in using technology. Before the implementation of information technology-based information systems, there were many mistakes made in providing services to patients, one of which was in the pharmaceutical department because not a few doctors wrote prescriptions that were not well read by the pharmacy department. Likewise nurses in providing nursing care in the delegation of doctors sometimes write not so clear that the error rate is very large This problem arises around the implementation of technology in health care settings but has not received adequate attention. This may be due to the subjective nature of various factors, but also due to the lack of coordinated efforts towards more theoreticallyinformed work (Cresswell and Sheikh [2])

The United States, which has the most extensive data, can show the nature of this problem. a decade ago, the Institute of Medicine estimated that 44,000-98,000 people die each year due to medical errors and errors that can be easily prevented (Kohn et al. [3]). The Institute of Medicine also estimates that about 1.5 million adverse drug side effects each year in the US during the mid-2000s (Aspden et al. [4]). It has long been known that many medical errors result from inadequacy in medical records, for example, due to the doctor's unreadable handwriting, wrong dosage choices, and drug-drug or allergy-drug interactions (Kohn et al. [3]).

The lack of nurses in the United States (Carrier et al. [5]), which makes it important to find ways to make health care provision more efficient without compromising the quality of information systems provides increased ability to transfer information that is be on time between doctors and nurses who care for the individual and maintain that record. One benefit and purpose of using electronic medical records is that patients can access their own records, which allows them to have greater ability to make intelligent health care 
decisions. For these reasons, its effect on managing health care from both a health and financial perspective, the US government has encouraged the development of Electronic medical records.

In Indonesia, electronic-based hospital information system is regulated based on the Minister of Health regulation number 1171 / MENKES / PER / VI / 2011 which states that every hospital is required to implement a Hospital information system. SIM RS is a data management system that is very fast, accurate, and produces a collection of interacting information to be provided to all levels of hospital management. According to Ery Rustiyanto [6], Hospital Management Information System (RS SIM) is a series of activities that cover all health services (hospitals) at all administrative levels that can provide information to managers for the management of health services in hospitals. Services included are Main Services (Front Office) and Administrative Services (Back Office)

Results Information from processed data can be used to make decisions, improve service efforts, control quality of services, assess productivity, simplify services, analyze benefits, and estimate needs, clinical education research, and program planning and evaluation. According to Izzati and Bayu [7] there is a relationship between technology that suits the needs of users, the level of satisfaction of nurses with the successful application of SIM RS, the better the nurse understands the technology of eating the easier and faster, and the easier the technology is used, the user will not feel satisfied and trust self.

Sadoughi, Azadi, \& Azadi [8] Explaining that there are various types of barriers to using Electronic Medical Record in nursing that show this problem as a multi-faceted problem that nurses do not have enough time to search for data is the first major barrier noted by almost $81 \%(n=17)$ of the studies reviewed were followed by a lack of knowledge about search skills $(66 \% ; \mathrm{n}=14)$ and access requirements $(38 \% ; \mathrm{n}=8)$. Thus concluding that there appears to be an important role for hospital management in providing nurses with sufficient time and access to online information while working and care managers with the IT team in providing the training needed to use electronic-based literature

\section{RESEARCH METHODS}

This research method uses the literature review method, in this research it does not only mean reading the literature, but rather in-depth and critical evaluation of research on a research topic, and then summarizes, analyzes and synthesizes its contents and presents it in the form of a survey paper.

\section{RESULTS AND DISCUSSION}

Electronic medical records can reduce a variety of problems, one of which reduces the burden of nursing work in the documentation system, so that the quality of the nurse's meeting with patients is very awake, (Marcus et al. [9]). In a recent review of published research, Buntin et al. [10]) and Jones et al. [11] show that this improvement in quality and safety is clearly present in the majority (62 and 56 percent, respectively) of recent studies of EMR implementation. However, the remaining research shows mixed results, or sometimes results that are mainly negative. Many observers also point to efficiency gains. For example, properly implemented, EMR can streamline a number of routine tasks to allow more time to be shifted to more substantive aspects of patient care, which is very important for overloaded health care personnel. In addition, EMR systems can potentially save hospitals and clinics money in many aspects of their operations so that the same health care can be provided at a cost that is not too expensive, which of course, frees up resources to overcome financial quality problems (Narattharaksa [1]).

One of the studies conducted at Bunda Harapan Hospital stated that there were several groups of nurses divided into three sections which looked at the length of work, age, and level of understanding of technology, from one of the age groups stating that the use of technologybased information systems weighed heavily on them. due to the lack of information from the provider in providing training for the use of an electronic hospital-based SIM, while there are some groups that are on average between the ages of 25 to 35 years of age stating they are ordinary and can follow the technological developments and demands of hospitals that are thirsty to run, only of course the factors of management that must continue to provide information and training in using technology-based management information systems, the results of the overall sample study say that they are very inconvenienced in using technology-based hospital SIM (Sartika Dewi, RR Tutik, [12]).

The use of Electronic Medical Records does not always contribute well to health services, in the use of technology one of the most highlighted is the appearance of the system, logging in for too long, the internet system that is always experiencing disruptions, and computerized system errors. From several users, one of them was the doctor's team, saying that the information system was not specific enough and still had to keep coordinating with other health teams demanding that some of the documentation systems continue to be done manually. (Blumenthal and Tavenner [13]).

The use of electronic medical records is also highly influenced by the method of supervision and direction from the leadership (Buntin et al. [10]). At the level of individual health care organizations, health care personnel also face difficulties being able to use the system even when they are implemented. Workload is a major problem. With a very heavy patient burden, doctors specifically find it difficult to devote time to learning new systems, or to taking on additional reporting tasks to enter data into the system, this also sometimes becomes a problem even for nurses (Kijsanayotin et al., [14]) 
Cresswell and Sheikh [2] categorize the factors that influence the adoption of electronic medical record innovations into three dimensions that are interrelated with adequate technology, stakeholder involvement, and organizational leadership. The purpose of this paper is to identify what factors influence the success of the Electronic Medical Record in the order of nursing services so that it can benefit both users in this case are Hospitals and Professional Nursing Organizations and as reference material for science and research related to the use of electronic medical records. Where every hospital in Indonesia based on SNARS states that every hospital is obliged to apply an electronic-based information and documentation system

In research conducted (Narattharaksa [1]) Nearly 80 percent of hospitals, both public and private, have implemented an electronic medical record. And show good results on patient care. Thailand is one of the largest countries implementing technology-based information systems in the health sector. An understanding of every health worker on the use of technology is very much needed. From the data reported that the most effective use of this electronic-based information system is the administration. For the self-care department, there are still many improvements reported, one of which is the interest and motivation of the nurse in using technology. The research also states that at the level of care there are still many problems in using EMR,

A survey of 728 nurses in 2014 stated that the use of Electronic Medical Records as workloads. From starting to open access for too long, the appearance that is not yet so simple, and less specific from the program is a challenge for ITs to continue to innovate as a material consideration to always improve service to patients. (Rozenblum et al., [15])

Cresswell and Sheikh [2] state that the success factors of using EMR are social, management, and financial factors. Broadly speaking The main problems in Cresswell and Sheikh [2]) conclude that the factors supporting the successful use of EMR are adequate financial systems, budgets, clear organizational goals, avoiding "mission creep"; adjust and support organizational processes, adapt and support medical decisions, good communication about users and among various stakeholders, involvement of key stakeholders during implementation, good communication between nurses and managerial whether the system that is made is in accordance with the needs in field, adequate basic computer skills, basic computer use training if needed, training on EMR systems, and good relations between service providers and users. In other studies mention that (Singh \& Mahapatra [16]) success in using EMR is divided into two dimensions, namely managerial and engineering, which are included in the majoral dimension, where the roles of leaders and policy makers are included in the nursing manager in good planning, organizing and monitoring systems. That the use of EMR must be in accordance with the needs of nursing services including in the assessment, formulation of diagnoses, as well as planning interventions which also includes planning for patients to go home with each other must be integrated. So the role of a manager in communicating with nurses as a user to continue to be done so that if there are problems both technically and managerially it can continue to be analyzed in improvements. While the technical dimension in it is the technical ability of nurses themselves in using technology in this case the computer system, the ability of nurses in the process of finding data and, technological information systems must be simple, as needed, and comprehensive. Based on this research in line with (Risling [17]) that it is important for nursing education institutions to equip each student to use computer technology because the demands for nursing services not only provide good and reliable nursing care but must also be able to do technology-based documentation, even in various institutions still equipped with basic computer techniques. But this is one of the initial capital for nurses in preparing themselves to work in hospitals that have been applied EMR. Even in the same study (Risling [17]) also said that nurses are not only reliable in using technology in the documentation system but should be able to create a practice-based technology system, so that the use of technology can be adapted to the needs of patients at that time or called Evidance Base Practice (EBF), Every nursing educator must be able to prepare students to face the challenges of technology-based nursing services, educational institutions can be the main vehicle in conducting clinical and empirical trials in research into the use of technology in nursing services (Risling [17]).

(Franzoni \& Assar [18]) stated that the use of technology in the learning system in each institution can also be a material for habituation for nurses in using computers and technology (Rapchak, Nolfi, Turk, Marra, \& O'Neil [19]) stated that the training conducted $90 \%$ of nurses in the hospital about the use of EMR which is integrated with other professions are intended so that nurses are able to work interpersonal with other health issues in using information systems Electronic-based Hospitals show significant results on the successful use of EMR in terms of the level of speed in services, time efficiency levels and the financing system is not too large.

(Myburgh et al. [20]) states that every Electronic Medicar Record must always be evaluated periodically to assess the success and deficiencies of each system and the process of repairing any deficiencies so that services to patients remain plagued and the burden of nurse work is not too heavy. other studies state that success in the use of EMR is very much determined by stakeholders, the factor of this leadership is to control and policy in the use of EMR because their welds EMR must use expensive costs and a good security system, (Rozenblum et al. [15])

According to (Jensen, Chan, Weiner, Fowles, \& Neale [21]) that the use of electronic medical records is very helpful for nurses in documenting, in the process of data storage, collection, but nurses must still know the coding system in each disease so as to minimize errors in documentation the managerial party should always carry 
out periodic evaluations and training in the use of specific EMRs

In the research conducted (Iriandani [22]) stated that the success in the use of SIM RS is the intention of the user in this case is a nurse, which is influenced by the ease and flexibility of the system to use, ease and speed to access, simplification of appearance, and security of the system itself.

\section{CONCLUSION}

The progress of information and technology is a challenge for every group including health. Technological advancements require maximum nursing services. (Singh \& Mahapatra [16]) Technological advances also make a person's behavior change, but changes in positive things that every individual including nurses should find it easier to use technology-based hospital information systems (Singh \& Mahapatra [16])

Based on the literature study above, it can be concluded that the factors that influence the successful use of Electronic Medical Records in the order of nursing services in hospitals can be seen from the factors of nurses as users that each nurse must be ready to face global changes in this case technological advances, because Hospital demands high on the quality of service to patients. Managerial factors that must continue to evaluate and establish communication with nurses related to the system and the problems encountered. The Information System Technique Factor itself must be easy to use, easy and fast to access, flexible and in accordance with the needs in care, so that the main objective of the EMR application is achieved, namely to increase the effectiveness and efficiency of nurses in providing nursing care to clients, especially at home sick Based on the above conclusions, the suggestion that the author can give is the need for ongoing training from the managerial in the use of technology-based hospital information systems, if needed for nurses who are aged over 35 who can not use computers provided basic training in the use of computerization, the need for nursing education institutions to provide computerized education not only in the curriculum but also in every academic system and learning method so that at work they are accustomed to using a computerized system, and the organizers of nursing education should give special encouragement and direction to prospective nurses in creating innovative projects on nursing service systems that can be accounted for both clinically and empirically so that information systems can be based on practical and current needs, and to the system organizers hospital-based electronic information should the information system should be made easier from the appearance, flexibility, access and speed of use, so nurses are more confident in using technology-based hospital information systems.

\section{REFERENSI}

[1] Narattharaksa, K., Speece, M., Newton, C., \& Bulyalert, D. 2016. Key success factors behind electronic medical record adoption in Thailand. Journal of Health, Organisation and Management, 30(6), 985-1008. https://doi.org/10.1108/JHOM-102014-0180

[2] Cresswell, K \& Sheikh, A 2013, Organizational issues in the implementation and adoption of health information technology innovations: An interpretative review', International journal of medical informatics, vol. 82, no. 5, pp. e73-e86. https://doi.org/10.1016/ j.ijmedinf.2012.10.007

[3] Kohn, L.T., Corrigan, J.M. and Donaldson, M.S., Eds. 1999. To Err Is Human: Building a Safer Health System. National Academy Press, Institute of Medicine, Washington DC.

[4] Aspden $\mathrm{P}$ et al, Preventing Medication errors: Quality Chasm Series. Nat'l Academy Press: 1sted, 2007

[5] Carrier, H.-L. Ma, H.E. Ramon, et al. 2011. Interregulation of Th17 cytokines and the IL-36 cytokines in vitro and in vivo: implications in psoriasis pathogenesis. J Invest Dermatol, 131 (2011), pp. 2428-2437

[6] Rustiyanto, Ery. 2010. Statistik Rumah Sakit Untuk Pengambilan Keputusan. Edisi Pertama. Graha Ilmu. Yogyakarta.

[7] Andika. Bayu S., dan Izzati Muhimmah. 2013. Evaluasi Faktor-Faktor Kesuksesan Implementasi Sistem Informasi manajemen Rumah Sakit di PKU Muhammadiyah Sruweng dengan Menggunakan Metode HOT Fit. Seminar Nasional Informatika Medis. Hal 78-86. November. 2013.

[8] Sadoughi, F., Azadi, T., \& Azadi, T. 2017. Barriers to using electronic evidence based literature in nursing practice: a systematised review. Health Information and Libraries Journal, 34(3), 187-199. https://doi.org/10.1111/hir.12186

[9] Marcus RN, Owen R, Kamen L, Manos G, McQuade RD, Carson WH, Aman MG: 2009. A placebocontrolled, fixed-dose study of ar-ipiprazole in children and adolescents with irritability associated with autistic disorder. J Am Acad Child Adolesc Psychiatry 48: 1110-1119,

[10] Buntin MB, Burke MF, Hoaglin MC, Blumenthal D 2011. The benefits of health information technology: A review of the recent literature shows predominantly positive results. Health Aff;

[11] Jones, S., Rudin, R., Perry, T., \& Shekelle, P. 2014. Health information technology: An updated systematic review with a focus on meaningful use. Annals of Internal Medicine, 160(1), 48-54. 
[12] Dewi Sartika, Rr. Tutik Sri Hariyati, Enie Novieastari. 2014. Self Efficacy Perawat dalam Penggunaan Sistem Informasi Keperawatan Di RSIA Bunda Jakarta: Studi Fenomenologi. Jurnal Keperawatan Indonesia, Volume 17, No.2, hal 65-73 pISSN 14104490, eISSN 2354-9203 10.7454/jki.v17i2.443

[13] David Blumenthal, M.D., M.P.P., and Marilyn Tavenner, R.N., M.H.A. 2010. The "Meaningful Use" Regulation for Electronic Health Records. The New England Journal of Medicine as published by New England Journal of Medicine. Massachusetts Medical Society

[14] Kijsanayotin, B., Pannarunothai, S., Speedie, S.M.: 2009. Factors influencing health information technology adoption in Thailand's community health centers: Applying the UTAUT model. International Journal of Medical Informatics 78(6), 404-416 (2009).

[15] Rozenblum, R., Jang, Y., Zimlichman, E., Salzberg, C., Tamblyn, M., Buckeridge, D., Tamblyn, R. 2011. A qualitative study of Canada's experience with the implementation of electronic health information technology. Cmaj, 183(5), 281-289. https://doi.org/10.1503/cmaj.100856

[16] Singh, S., \& Mahapatra, R. K. 2017. Perceptions of Electronic Information Resources Usage and Issues with Nursing Academia in India. Chinese Librarianship: An International Electronic, (44), 2332.

[17] Risling, T. 2017. Educating the nurses of 2025: Technology trends of the next decade. Nurse Education in Practice, 22, 89-92. https://doi.org/10.1016/j.nepr.2016.12.007

[18] Franzoni, A. L., \& Assar, S. 2009. Student Learning Styles Adaptation Method Based on Teaching Strategies and Electronic Media. Educational Technology \& Society, 12 (4), 15-29

[19] Rapchak, M. E., Nolfi, D. A., Turk, M. T., Marra, L., \& O’Neil, C. K. 2018. Implementing an interprofessional information literacy course: impact on student abilities and attitudes. Journal of the Medical Library Association, 106(4), 464-470. https://doi.org/10.5195/JMLA.2018.455

[20] Myburgh, H., Murphy, J. P., Van Huyssteen, M., Foster, N., Grobbelaar, C. J., Struthers, H. E., Peters, R. P. H. 2015. Implementation of an electronic monitoring and evaluation system for the antiretroviral treatment programme in the Cape Winelands District, South Africa: A qualitative evaluation. PLoS ONE, 10(5), 1-23. https://doi.org/10.1371/journal.pone.0127223

[21] Jensen, R. E., Chan, K. S., Weiner, J. P., Fowles, J. B., \& Neale, S. M. 2009. Implementing Electronic Health Record-Based Quality Measures for Developmental Screening. Pediatrics, 124(4), e648e654. https://doi.org/10.1542/peds.2008-3091
[22] Iriandani. 2014. Evaluasi Kesuksesan "Sistem Informasi Manajemen (SIM-RS) pada Rumah Sakit Jiwa Menur Surabaya" Menggunakan Information System Success Model (ISSM), (4), 1-7. 